\title{
Centrifuge modeling of one-step outflow tests for unsaturated parameter estimations
}

\author{
H. Nakajima ${ }^{1, *}$ and A. T. Stadler ${ }^{1, * *}$ \\ ${ }^{1}$ Geoscience Research, Idaho National Laboratory, Idaho Falls, Idaho, USA \\ *now at: Center for Deep Geological Environments, National Institute of Advanced Industrial Science and Technology \\ (AIST), Tsukuba, Ibaraki, Japan \\ *** now at: URS Corporation, Cleveland, Ohio, USA
}

Received: 9 March 2006 - Published in Hydrol. Earth Syst. Sci. Discuss.: 16 May 2006

Revised: 2 August 2006 - Accepted: 25 September 2006 - Published: 5 October 2006

\begin{abstract}
Centrifuge modeling of one-step outflow tests were carried out using a 2-m radius geotechnical centrifuge, and the cumulative outflow and transient pore water pressure were measured during the tests at multiple gravity levels. Based on the scaling laws of centrifuge modeling, the measurements generally showed reasonable agreement with prototype data calculated from forward simulations with input parameters determined from standard laboratory tests. The parameter optimizations were examined for three different combinations of input data sets using the test measurements. Within the gravity level examined in this study up to $40 \mathrm{~g}$, the optimized unsaturated parameters compared well when accurate pore water pressure measurements were included along with cumulative outflow as input data. With its capability to implement variety of instrumentations under well controlled initial and boundary conditions and to shorten testing time, the centrifuge modeling technique is attractive as an alternative experimental method that provides more freedom to set inverse problem conditions for the parameter estimation.
\end{abstract}

\section{Introduction}

Modeling unsaturated flow in the vadose zone or the mechanical behavior of soil under unsaturated conditions requires knowledge of the unsaturated hydraulic properties, i.e., the relationship between pore water pressure $(p)$, water content $(\theta)$, and hydraulic conductivity $(K)$ of the soil. Most laboratory methods require either static or steady-state flow conditions, hence they are time-consuming. The inverse method, which estimates soil hydraulic properties from transient tests, has been increasingly used since it requires a much shorter testing time than steady-state methods. In addition, the in-

Correspondence to: H. Nakajima

(nakajima.hideo@aist.go.jp) verse method allows the simultaneous estimation of both the soil water retention and the unsaturated hydraulic conductivity function from a single transient experiment (Hopmans et al., 2002).

Kool et al. (1985) provided a detailed description of the framework for inverse methods and estimated three parameters in the van Genuchten model (van Genuchten, 1980) based on numerical and experimental data (Parker et al., 1985) of one-step outflow tests. Their results indicated that an accurate solution of the parameter identification problem can be obtained when (i) the input data include the cumulative outflow volumes with time corresponding to at least half of the final outflow, and the final outflow volume, (ii) the final cumulative outflow corresponds to a sufficiently large fraction (e.g., >0.5) of the total water between saturated and residual water contents, (iii) experimental error in the outflow measurements is low, and (iv) initial parameter estimates are reasonably close to their true values. Sensitivity to errors and the solution uniqueness of inverse methods with one-step tests have been further investigated (e.g., Toorman, 1992; van Dam et al., 1992). Toorman (1992) showed, from their analysis of the objective function using the van Genuchten model and numerical data sets, that uniqueness problems can be minimized if the cumulative outflow is supplemented with pore water pressure measurement data.

Since it is impractical to conduct one-step gravity driven tests that fulfill the aforementioned first two conditions suggested by Kool et al. (1985) (for example, several days of observation of drainage from a 2 to $3 \mathrm{~m}$ tall soil column may be required even for sand), pneumatic pressure or suction is usually applied at the top or bottom of small soil samples. However, such test configurations may result in non-uniform flow conditions. Hopmans et al. (1992) applied x-ray tomography during one-step tests for initially saturated soil samples and found preferential flow. Since the governing flow equations in inverse methods are based on the uniform Darcian

Published by Copernicus GmbH on behalf of the European Geosciences Union. 
flow condition, the predicted parameters using observational data taken under non-uniform flow conditions are not accurate.

Multi-step tests, in which applied pneumatic pressure or suction is changed stepwise with small increments, have also been conducted (Eching and Hopmans, 1993; Eching et al., 1994; van Dam et al., 1994). van Dam et al. (1994) carried out both one-step and multi-step experiments and compared the optimized parameters using only cumulative outflow as the input data. Their results showed that multi-step tests can contain sufficient information for unique estimates while one-step tests show poorer estimations. On the other hand, Eching and Hopmans (1993) conducted both one-step and multi-step outflow experiments, and with the inclusion of pore water pressure data in the inverse methods, both onestep and multi-step methods gave excellent results with the optimized parameters agreeing well with the independently measured $p-\theta$ data. Since the multi-step tests took twice as long to perform as the one-step tests, it was concluded that the one-step test is still an attractive option if pore water pressure measurements are available.

Instead of applying pneumatic pressure or suction, onestep tests can be also carried out under centrifugally accelerated fields. Applying a centrifugal force to a small sample for measurements of water content and saturated or unsaturated conductivity has become standard in the fields of hydrology and petroleum engineering (Russell and Richards, 1938; Hassler and Brunner, 1945; Hagoort, 1980). By the large driving force induced by centrifugal acceleration, measurements of extremely low hydraulic conductivity and water content are possible in a short time. However, the majority of such centrifuge applications have in the past been essentially static or steady-state methods in which a $p-\theta$ or $K-\theta$ profile is constructed from a series of single measurements at equilibrium or a steady condition; thus, they still require repeating tests varying the magnitude of the centrifugal force (Khanzode et al., 2000; Alemi et al., 1976; Nimmo et al., 1987). Additionally, since the type of centrifuge apparatuses that are used for such hydraulic property determinations typically have relatively short rotation radii on the order of $0.1 \mathrm{~m}$, the radial variations in the centrifugal acceleration need to be taken into account in analyses.

Recently Simunek and Nimmo (2005) examined the feasibility of centrifuge tests coupled with the inverse method. They developed a numerical code and carried out parameter optimization using multi-rotation transient flow tests in a centrifuge. Their numerical code is particularly noteworthy in the sense that it takes account of radial variations of centrifugal acceleration in the governing equation, and hence can directly or inversely simulate unsaturated water flow in a transient centrifugal field. From their centrifuge tests, transient water contents at several rotational speeds were obtained using electrical conductivity measurements and used as input data. The optimized soil hydraulic properties compared well with those determined using equilibrium analy- sis and steady state experiments, especially for intermediate pressure heads between -0.5 and about $-3 \mathrm{~m}$. The work by Simunek and Nimmo (2005) provided significant insight into the usefulness of the application of centrifugal force as an alternative method for rapid hydraulic parameter estimation.

On the other hand, centrifuge force has also been utilized for several decades in geotechnical engineering fields to conduct scaled model tests for studies on soil mechanical behavior or contaminant movement in groundwater (Taylor, 1995; Garnier, 2001). The centrifuge may be useful for scale modeling of any large-scale nonlinear problem for which gravity is a primary driving force. Having an adequately large radius of rotation, centrifuge scale modeling assumes that the uniform centrifugal acceleration is subject to the model. Geometry and time scales are reduced based on scaling laws, and observations in the centrifuge scaled model can be treated as representative of prototypes in which geometry and time scales are much larger and longer.

If unsaturated flow is properly scaled, centrifuge scaled modeling of a one-step test is attractive as an alternative technique. A large centrifuge is capable of carrying out model tests for relatively large soil samples, hence a variety of measurements such as outflow volume, pore water pressures and water contents are possible, and there is more flexibility in the experimental boundary conditions than in tests using a small centrifuge. In addition, since centrifuge scaled modeling interprets observed phenomena in its prototype under natural gravity, special consideration of radial variations of centrifugal force for inverse models may not be necessary.

Since Arulanandan et al. (1988) analyzed scaling similitude of centrifuge modeling for flow and transport problems, the applications of centrifuge modeling techniques have been extended to various problems, including miscible contaminant transport in saturated and multi-phase flow problems (e.g., Hensley and Schofield, 1991; Nakajima et al., 1998, 2005; Oung et al., 2005). While these works proved the usefulness of centrifuge modeling, they have also shown that centrifuge scaling similitude is not always conserved (e.g., Arulanandan et al., 1988; Goforth, 1991; Cooke and Mitchell, 1991; Culligan and Barry, 1998). Culligan and Barry (1998) used experimental results to analyze the scaling laws for multiphase flow in centrifuge models. It was considered that scaling similitude in a centrifuge model depends on the characteristic length scale that governs fluid flow. When fluids move as a plume or have continuity, the controlling length is considered to be macroscopic (e.g., plume depth). On the other hand, when pore fluid exists as an isolated condition (e.g., pore water under a pendular condition), the controlling length is microscopic, (e.g., pore scale), and similitude is no longer conserved. The authors concluded that the centrifuge model does not perfectly scale multiphase conditions since there are situations where both microscopic and macroscopic length scales govern specific phenomena under multiphase conditions. However, the magnitude of violation of scaling similitude depends on the unsaturated condition of 
interest and the magnitude of the applied centrifugal gravity. Several researchers investigated scaling similitude for unsaturated flow by considering heights of capillary rise in a centrifuge model (Burkhart et al., 2000; Crancon et al., 2000; Khalifa et al., 2000; Knight et al., 2000; Thorel et al., 2000; Rezzoug, 2004). The conservation of similitude for capillary rise agreed with the theoretical consideration of Culligan and Barry (1998) since the capillary rise occurs where the pore water is in continuous phase with relatively high saturation, hence the controlling length is macroscopic (i.e., capillary height).

If the discrepancy of scaling similitude is negligibly small for a one-step drainage condition, the centrifuge modeling technique may be applicable for parameter estimation. The validity of centrifuge modeling for parameter estimation was partially supported by the work of Cooke (1994). The author carried out one-step tests using the centrifuge modeling technique and found that good agreement with parameters from standard tests was obtained when only one parameter was estimated; whereas three parameter estimations showed somewhat poor agreement. The work by Cooke (1994) proved the potential validity of the centrifuge modeling technique for parameter estimation. However, since only cumulative outflow was taken as an input data, it remains unclear if the poor estimation was lead by insufficient input data or by violation of scaling similitude.

The focus of this research is to examine if the addition of pore water pressure measurements to one-step tests utilizing a centrifuge modeling technique is beneficial for parameter estimation. For this purpose, one-step tests were performed using a 2-m radius geotechnical centrifuge under different centrifugal gravity fields, and the measured cumulative outflow and pore water pressures were then used for parameter estimations. The test results were compared with those obtained from conventional direct tests.

\section{Inverse method with one-step test}

The experimental procedure consists of measuring cumulative outflow and pore water pressures as functions of time during monotonic drainage from an initially saturated soil sample. Pore water is allowed to drain from the base of the soil sample through a screen layer. The drainage driven by the pressure gradient and gravity is assumed to follow Richards' equation. The one-dimensional form with the vertical coordinate, $z$, taken to be positive downward, is written as

$\frac{\partial \theta}{\partial t}=\frac{\partial}{\partial z}\left[K(h)\left(\frac{\partial h}{\partial z}-1\right)\right]$

where $t$ is time and $h=p / \gamma_{w}$ is the pressure head. $\gamma_{w}$ is the unit weight of water. The initial and boundary conditions for the two-layer system (soil sample and the screen layer) are

$h=h_{0}(z), \quad t=0, \quad 0 \leq z \leq L$ $\frac{\partial h}{\partial z}=1, \quad t>0, \quad z=0$

$h=h_{L}, \quad t>0, \quad z=L$

where $z=0$ is taken at the top of the soil sample, $z=L$ at the bottom of the screen layer, and $h_{L}$ is the pressure head at the bottom of the screen layer. For the screen layer, only the saturated hydraulic conductivity needs to be known if it remains saturated during the test. The van Genuchten model is assumed to adequately describe the unsaturated hydraulic properties:

$\bar{S}= \begin{cases}\frac{1}{\left(1+|\alpha h|^{n}\right)^{1-1 / n}} & h<0 \\ 1 & h \geq 0\end{cases}$

$K(\bar{S})=K_{S} \bar{S}^{\nu}\left[1-\left(1-\bar{S}^{n /(n-1)}\right)^{1-1 / n}\right]^{2}$

$\bar{S}=\frac{\theta-\theta_{r}}{\theta_{S}-\theta_{r}}$

where $\bar{S}$ is the effective saturation, $\theta_{r}$ and $\theta_{s}$ are the residual and saturated water contents, respectively, $v$ is a lumped parameter that accounts for pore tortuosity and connectivity, $\alpha$ and $n$ are empirical parameters, and $K_{s}$ is the saturated hydraulic conductivity of soil. The $K-\theta$ model is based on the capillary model of Mualem (1976) in conjunction with the use of Eq. (5). Mualem (1976) found that $v$ equal to 0.5 was an optimal value for many soils and is the most common default value used with $K_{s}$ in Eq. (6). Based on this, the value 0.5 was also adopted for $v$ in this study. However, it should be noted that a single, optimal $v$ value for predictive use has not been established at this time. With $K_{S}$ as an additional unknown parameter, Schaap and Leij (2000) suggested that using the value -1 for $v$ is particularly effective for coarse textured soils when estimating the soil water retention and hydraulic conductivity functions simultaneously. $\theta_{s}$, which is the same as the porosity of the soil sample, is taken as a known parameter for this study.

The use of Eqs. (5) through (7) implies that the optimization of the parameters, $\theta_{r}, \alpha, n$, and $K_{s}$ will yield a numerical solution that matches the cumulative outflow and pore water pressure head observations from experiments. The objective function to be minimized by the inverse method is

$$
\begin{aligned}
E(\boldsymbol{b})= & \sum_{i=1}^{N_{1}}\left[w_{i}\left[Q\left(t_{i}\right)-\hat{Q}\left(t_{i}, \boldsymbol{b}\right)\right]\right]^{2} \\
& +\sum_{j=1}^{N_{2}} \sum_{k=1}^{N_{3}}\left[v_{1_{j}} v_{2_{k}}\left[h\left(z_{j}, t_{k}\right)-\hat{h}\left(z_{j}, t_{k}, \boldsymbol{b}\right)\right]\right]^{2}
\end{aligned}
$$

where $\boldsymbol{b}$ is a vector containing the optimized parameters such as $\theta_{r}, \alpha, n$, and $K_{s} . Q\left(t_{i}\right)$ is the observed cumulative outflow per unit area at a specific time $t_{i}$, and $h\left(z_{j}, t_{k}\right)$ is the observed pore water pressure head at a depth of $z_{j}$ and at a time 
Table 1. Scaling relationship of a centrifuge model with a scale factor $N$ (Arulanandan et al., 1988).

\begin{tabular}{lcc}
\hline \multicolumn{1}{c}{ Parameter } & & Prototype/model ratio \\
\hline Gravity, & $g$ & $1 / N$ \\
Macroscopic length, & $l_{\text {macro }}$ & $N$ \\
Microscopic length, & $l_{\text {micro }}$ & 1 \\
Pore fluid velocity, & $v$ & $1 / N$ \\
Time, & $t$ & $N^{2}$ \\
Pore fluid pressure, & $p$ & 1 \\
Hydraulic conductivity, & $K$ & $1 / N$ \\
Intrinsic permeability, & $k$ & 1 \\
Soil porosity, & $\phi$ & 1 \\
Fluid density, & $\rho$ & 1 \\
Fluid viscosity, & $\mu$ & 1 \\
Interfacial tension, & $\sigma$ & 1 \\
\hline
\end{tabular}

$t_{k} . \hat{Q}\left(t_{i}, \boldsymbol{b}\right)$ and $\hat{h}\left(z_{j}, t_{k}, \boldsymbol{b}\right)$ are numerically calculated values of the cumulative outflow and the pore water pressure head, respectively. The subscripts $N_{1}, N_{2}$, and $N_{3}$ are the numbers of observations of cumulative outflow and pore water pressure head. $w, v_{1}$, and $v_{2}$ are the weighting factors that can be used to individually weigh each measured data point.

The optimization was implemented using the HYDRUS1D code that solves Richards' equation numerically using Galarkin type linear finite element schemes, and implements a Marquardt-Levenberg type parameter estimation technique for the inverse estimation of selected soil hydraulic parameters from measured transient flows (Simunek et al., 1998).

\section{Centrifuge modeling}

\subsection{Scaling laws of centrifuge modeling}

The basic principles of centrifuge modeling are; (i) increase of self weight as much as $N$ times by increases of acceleration equal to the reduction of model length scale as small as $N$ times, and (ii) reduction of time for model tests as the scale is reduced. $N$ is the scale factor. In essence, the principle of centrifuge modeling is to raise the acceleration of the scaled model to obtain prototype pressure/stress levels in the model.

The scaling relationship of the centrifuge model at $\mathrm{Ng}$, where the same soil and pore fluid are used in both the model and its prototype, is shown in Table 1 (Arulanandan et al., 1988). While this relationship is self-evident or well-established for saturated flow conditions, more careful attention needs to be paid to unsaturated conditions where the capillary force could be much larger than the body force. Culligan and Barry (1998) defined the following dimension-

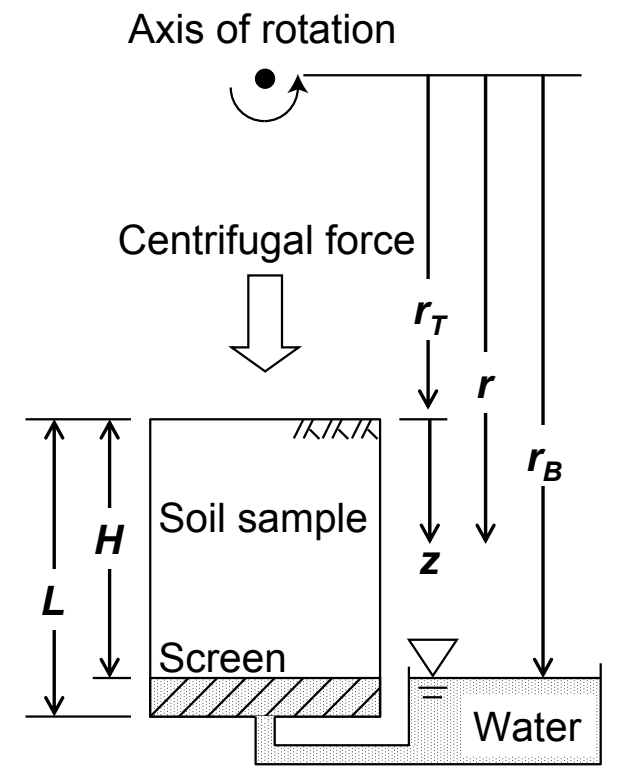

Fig. 1. Cross-sectional diagram of a soil sample in a centrifugal field, with free water establishing a hydrostatic pressure boundary condition at the bottom of the sample.

less numbers for analyzing the scaling relationship for multiphase flow conditions.

$\begin{aligned} C_{a} & =\frac{v \mu l_{\text {micro }} \delta x}{\sigma k} \\ B_{o} & =\frac{\rho g l_{\text {micro }} \delta x}{\sigma}\end{aligned}$

where $l_{\text {micro }}$ is the characteristic fluid interfacial radius, $\delta x$ is the controlling length, and $k$ is the intrinsic permeability of the soil. Eqs. (9) and (10) are known as the capillary number and Bond number, representing the relative importance of the viscous force to the capillary force, and the body force to the capillary force, respectively. Because $\delta x$ may vary under different circumstances, these dimensionless numbers should be evaluated at least with respect to the macroscopic and microscopic controlling lengths. Table 2 shows the scaling relationship of these dimensionless numbers assuming that the scaling relationship of the flow velocity shown in Table 1 also follows for unsaturated conditions. These relationships suggest that when the controlling length for a problem is macroscopic, similitude between a centrifuge model and the prototype can be achieved. Otherwise, direct scaling of data from a centrifuge model to the prototype is not possible.

For a one-step drainage test, starting from a fully saturated condition and lowering the water table from the soil surface to the bottom, pore water initially exists as an entirely continuous phase. During the drainage process, decreases in pore water pressure and in saturation occur simultaneously. With a sufficiently small pore water pressure, a small volume of 
Table 2. Scaling relationship of dimensionless numbers.

\begin{tabular}{lcc}
\hline \multicolumn{2}{c}{ Dimensionless number } & Prototype/model ratio \\
\hline Macroscopic capillary number, & $C_{a}{ }^{*}=\frac{v \mu l_{\text {micro }} l_{\text {macro }}}{\sigma k}$ & 1 \\
Microscopic capillary number, & $C_{a}=\frac{v \mu l_{\text {micro }}^{2}}{\sigma k}$ & $1 / N$ \\
Macroscopic Bond number, & $B_{o}{ }^{*}=\frac{\rho g l_{\text {micro }} l_{\text {macro }}}{\sigma}$ & 1 \\
Microscopic Bond number, & $B_{o}=\frac{\rho g l_{\text {micro }}^{2}}{\sigma}$ & $1 / N$ \\
\hline
\end{tabular}

water could eventually be isolated and form a pendular saturation condition. This is likely to be seen near the soil surface where the pore water pressure is smallest in the soil sample. When drainage ceases and an equilibrium condition is established, pore water distributes from full saturation at the bottom to pendular saturation at the top, depending on the sample height. This means that the phase of the pore water is initially entirely continuous, but that it varies being both spatially and temporally discontinuous. Consequently, the "exact" similitude of one-step drainage is not likely satisfied between a centrifuge model and the prototype; however, the magnitude of the deficiency in the scaling laws due to the coexistence of different controlling lengths is not well understood. If the deficiency is negligible, the application of a conventional scaling laws may still be reasonable in practice.

\subsection{Uniformity of centrifugal acceleration}

In this section, pore water pressure distributions in the centrifuge model and its prototype are compared to evaluate the rationality of assuming a uniformly accelerated gravity field for centrifuge modeling. Figure 1 shows a soil column of length $H$ (i.e., $L$ minus thickness of screen layer) subject to centrifugal rotation. For simplicity, pore water pressure distribution at equilibrium condition is considered here. Water pressure at the bottom of the soil is maintained at an atmospheric pressure. The pore water pressure under the equilibrium condition can be expressed as a function of the angular velocity $\omega$ and the radius $r$

$$
\begin{aligned}
p(r) & =\int_{r_{B}}^{r} \rho r \omega^{2} d r \\
& =\frac{1}{2} \rho \omega^{2}\left(r^{2}-r_{B}^{2}\right)
\end{aligned}
$$

where $p(r)$ is pore water pressure at radius $r$ and $r_{B}$ is radius at the bottom of the soil. Suppose the rotational speed is configured to create a pore water pressure of the model identical to the prototype at a reference radius $r_{\text {ref }}$,

$$
\frac{1}{2} \rho \omega^{2}\left(r_{\mathrm{ref}}^{2}-r_{B}^{2}\right)=-\rho g\left\{N\left(r_{B}-r_{\mathrm{ref}}\right)\right\}
$$

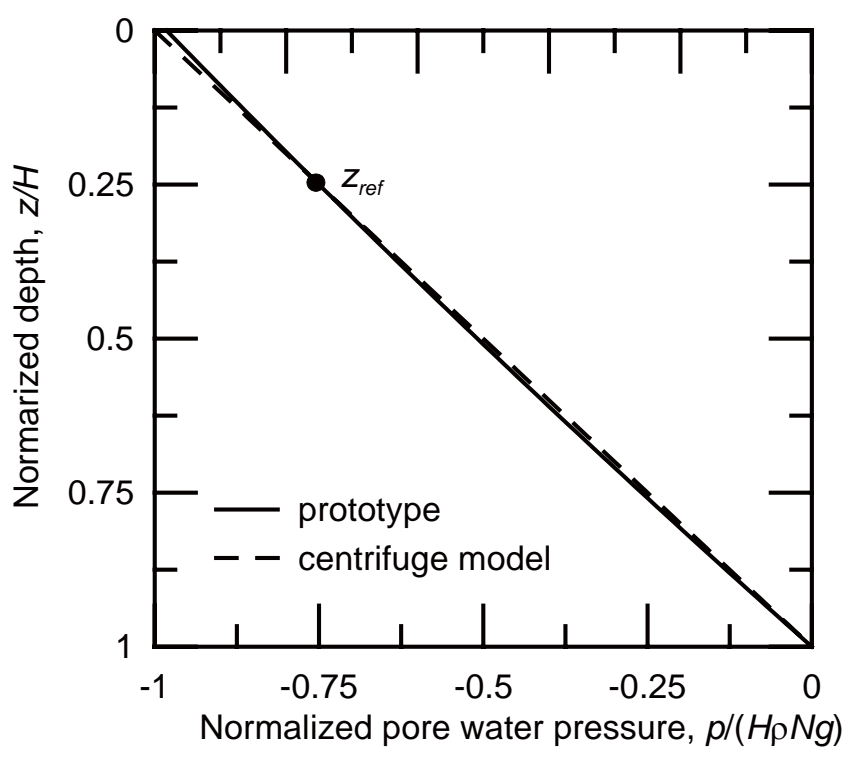

Fig. 2. pore water pressure distribution at the equilibrium condition in the centrifuge model and its prototype $\left(r_{T}=1.57 \mathrm{~m}, r_{B}=1.82 \mathrm{~m}\right.$, $\left.z_{\text {ref }} / H=0.25\right)$.

Then the angular velocity is determined as

$\omega=\sqrt{\frac{2 N g}{2 r_{\text {ave }}+z_{\text {ref }}}}$

where $r_{\mathrm{ave}}=\left(r_{B}+r_{T}\right) / 2$ is the average radius of the sample, $r_{T}$ is radius at the soil surface, and $z_{\text {ref }}=r_{\text {ref }}-r_{T}$ is the depth from the soil surface to the reference point. In this case, the pore water pressure of the model at other depths becomes

$p(z)=\frac{2 \frac{r_{\mathrm{ave}}}{H}+\frac{z}{H}}{2 \frac{r_{\mathrm{ave}}}{H}+\frac{z_{\text {ref }}}{H}} \rho N g(z-H)$.

Figure 2 compares pressure distributions of the centrifuge model and the prototype. Due to the non-linearity in the fractional term of Eq. (14), the pressure distribution of the centrifuge model differs from the prototype except at $z=H$ 


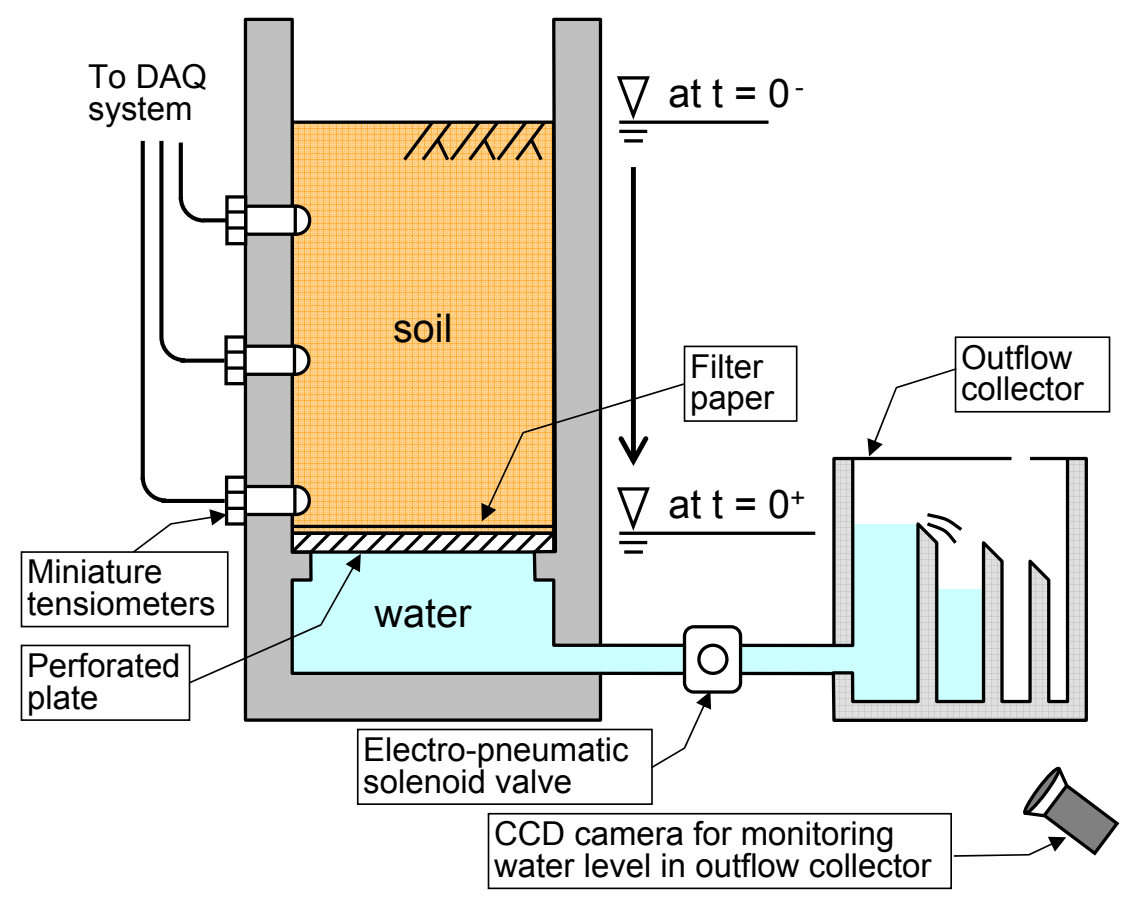

Fig. 3. Centrifuge test setup.

and $z_{\text {ref. }}$. However, with a large ratio of the radius relative to model size, i.e., $r_{\text {ave }} / H$, the difference can be reduced. In this study, soil samples having a length of $0.25 \mathrm{~m}$ or shorter were tested with the 2-m radius centrifuge apparatus, and the $r^{2}$ value of the linear regression for the pore water pressure distribution in the model has a yield higher than 0.999. Thus, it is reasonable to assume that effect of the radial variation of centrifugal acceleration on pore fluid behavior is small and that the entire soil sample is subject to $N$ times larger gravity $(\mathrm{Ng})$ in the centrifuge.

\section{Experimental setup and procedures}

\subsection{Centrifuge model tests}

Centrifuge tests were performed using a geotechnical centrifuge at the Idaho National Laboratory (Smith et al., 2002). The test system shown in Fig. 3 consists of a cylindrical test cell, $102 \mathrm{~mm}$ in diameter and $432 \mathrm{~mm}$ in height, and an outflow collector. A $10 \mathrm{~mm}$ thick perforated plate with filter paper (Whatman \#1) on the top face was installed directly above the reservoir to allow free drainage and to prevent the migration of soil particles into the reservoir. The saturated hydraulic conductivity of the perforated plate, coupled with the filter paper, was determined from constant head permeability tests to be $5.5 \times 10^{-5} \mathrm{~m} / \mathrm{s}$.

Miniature tensiometers were used to measure the transient pore water pressure along the soil column. The tensiome- ters used here consisted of two brass fitting components; one with a gauge pressure transducer (Honeywell 26PCB) and the other with a porous ceramic cup of $6 \mathrm{~mm}$ in diameter. From calibration tests, it was confirmed that the transducers maintained their linear output and that variation of the pressure readings was about $20 \mathrm{~Pa}(2 \mathrm{~mm}$ in pressure head) even at $40 \mathrm{~g}$. Each ceramic cup and pressure transducer was glued to the corresponding fitting with epoxy adhesive. In order for the tensiometers to instantaneously measure the pore water pressure, the ceramic cups were saturated and the water reservoir space inside the fittings was de-aired. Prior to being installed onto the test cell, the tensiometers were prepared using the following procedure. First, the fittings of the transducer and the ceramic components were connected firmly with the ceramic cup in an air-dry condition. Second, dry tensiometers were placed in a vacuum chamber to evacuate air (Fig. 4). Maintaining a vacuum for two hours, de-aired water was introduced into a water pool to submerge the ceramic cups. A vacuum was applied for a total of three hours and then slowly released. Due to the pressure difference between the inside and outside of the ceramic cup, de-aired water was absorbed into the water reservoir space through the ceramic cup.

For all of the experiments, fine Ottawa sand (U.S. Silica, F110), with a mean particle diameter $\left(D_{50}\right)$ of $0.1 \mathrm{~mm}$ and a uniformity coefficient $\left(C_{u}\right)$ of 1.6 was used as the porous medium. After the tensiometers were installed in the ports on the side wall of the test cell, dry sand was uniformly packed. The bulk dry density was occasionally measured during the 


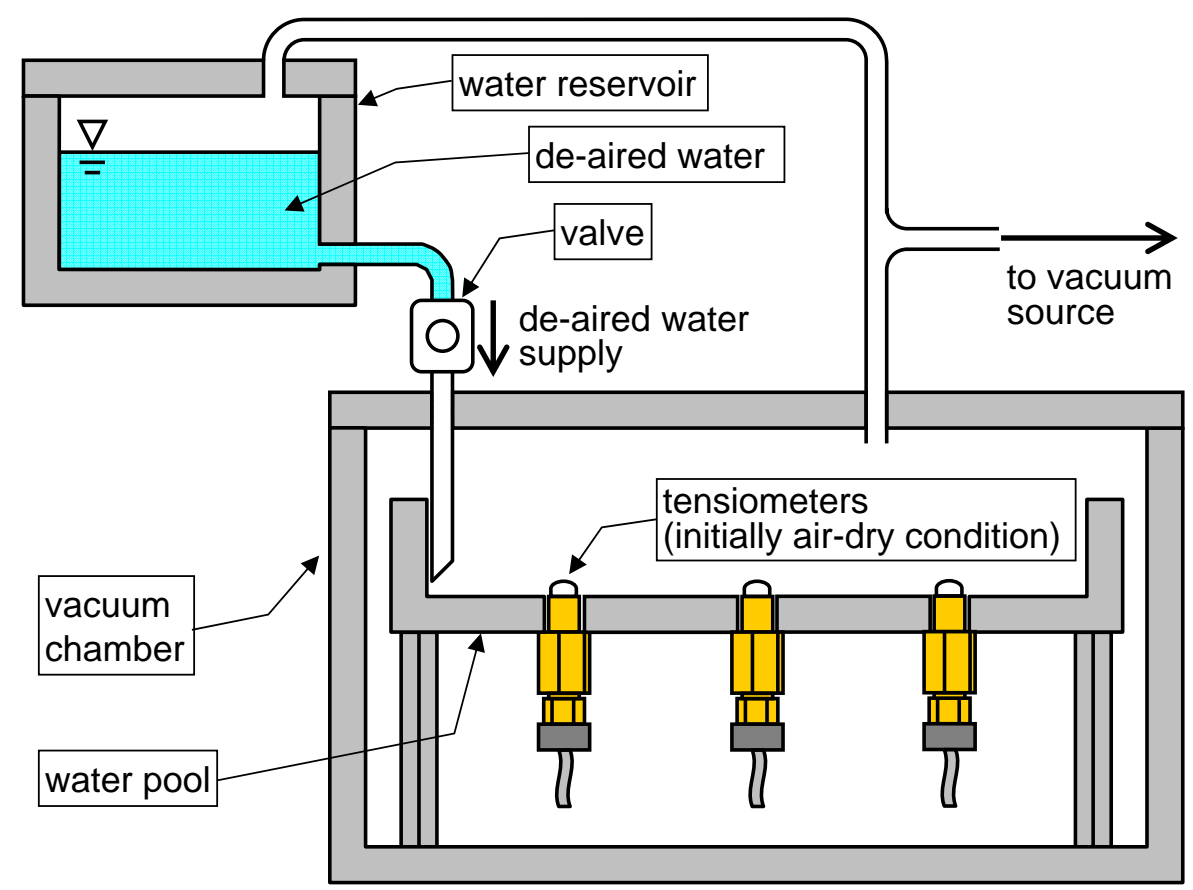

Fig. 4. Saturation of tensiometers.

packing to ensure uniformity of the sample. After the soil sample was packed to a specified height, the container was placed in a large vacuum chamber. A vacuum was applied to the sample for approximately $3 \mathrm{~h}$ and de-aired water was then introduced into the sample from a port located below the soil sample. Once the water level reached the soil surface, the vacuum pressure was released. After removing excess water and exactly adjusting the water level to the soil surface, the test specimen was weighed to calculate the degree of saturation. The porosity of test samples was approximately 0.37 , ranging between 0.362 and 0.377 , and the initial saturation was more than $97 \%$ for all of the tests.

The soil filled container was then placed on the centrifuge platform and the reservoir port was connected to the outflow collector. The test container and the outflow collector were connected using $13 \mathrm{~mm}$ I.D. plastic tubing and an electropneumatic valve, which had a relatively large orifice opening (flow coefficient $=6$ ) and was chosen to reduce the energy loss when water passed through the valve. The on/off operation of the valve was virtually instantaneous.

The outflow collector consisted of 6 sections connected in series, with a reduction in cross-sectional area at each successive section. This design ensured a sufficient degree of resolution for the outflow volume measurements by visualizing the movement of the water level in each section. The first section was filled with water to the height of the overflow slit. The height of the water level in the first section coincided with the bottom of the soil sample. To initiate an experiment, the valve was opened at the designated centrifu- gal acceleration, and the cumulative outflow discharged from the bottom of the sample through the reservoir was collected in the outflow collector. By allowing water to overflow from the first section of the outflow collector, the water level in the first section was maintained constant at the height of the soil sample bottom. Therefore, the perforated base plate was maintained saturated during the test. As the water reached the top of each section, water overflowed into each successive section.

As the drainage progressed, a sufficient amount of water level rising in the smaller sections could be visualized with a video camera placed in front of the collector. Snapshots at given times were taken as 640-480 bitmap images. For each snapshot, number of pixels between the bottom of a section and the water level was measured. Then height of the water level was calculated using a correlation factor, i.e., length per unit pixel which was determined from number of pixels between two points of known distance. Knowing the cross-sectional area of each section and the height of water level, the cumulative outflow volume was obtained. The accuracy of the outflow volume measurements depends on the resolution of the images plus size of the cross-sectional area of the sections. The accuracy ranged between \pm 1500 to $\pm 400 \mathrm{~mm}^{3}$, and that for outflow per unit area of the sample was between $1.9 \times 10^{-1}$ and $4.9 \times 10^{-2} \mathrm{~mm}^{3} / \mathrm{mm}^{2}$.

For each test, drainage was monitored for approximately two hours. After terminating the outflow observations, the centrifuge was stopped and the sample height was measured to ascertain if any significant settlement had occurred. 
Table 3. Centrifuge test conditions.

\begin{tabular}{ccccc}
\hline Test code & $\begin{array}{c}\text { Applied } \\
\text { gravity } \\
{[N g]}\end{array}$ & $\begin{array}{c}\text { Soil } \\
\text { height } \\
H[\mathrm{~mm}]\end{array}$ & $\begin{array}{c}\text { Height in } \\
\text { prototype scale } \\
N \times H[\mathrm{~m}]\end{array}$ & $\begin{array}{c}\text { Screen layer thickness } \\
\text { in prototype scale } \\
N \times(L-H)[\mathrm{mm}]\end{array}$ \\
\hline 10A, 10B & 10 & 254 & 2.54 & 100 \\
20A, 20B & 20 & 127 & 2.54 & 200 \\
40A, 40B & 40 & 64 & 2.54 & 400 \\
\hline
\end{tabular}

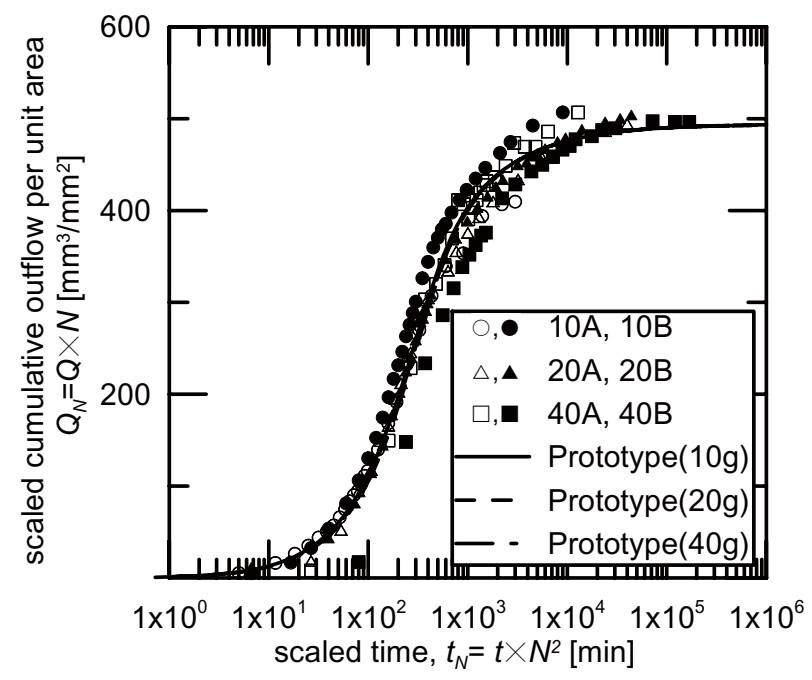

Fig. 5. Scaled cumulative outflow versus scaled time: subscript $N$ denotes scaled quantity.

Measured settlements were $1 \mathrm{~mm}$ or less for all tests. The corresponding changes of porosity were at most 0.016 and so were assumed to be insignificant.

\subsection{Prototype of the centrifuge models}

The centrifuge tests performed are summarized in Table 3. A pair of tests was carried out at each of three different $g$-levels $(10 g, 20 g$, and $40 g)$. The theoretical prototypes represented by the centrifuge models are one-dimensional gravity-driven drainages from a $2.54 \mathrm{~m}$ tall soil column laid on a screen layer, where the water table instantaneously changes from the surface to the bottom of the soil sample. As described in the previous section, inverse methods solve for the two-layer system of soil and the underlying screen layer. Therefore, the thickness of the screen layer for the prototype must also be scaled. The prototype thickness of the perforated plate, which actually is $10 \mathrm{~mm}$, also depends on the scale factor $N$.

Prior to the centrifuge tests, constant head permeability tests and hanging-column tests for the sand prepared using the same packing method were carried out. The $K_{s}, \alpha, \theta_{r}$, and $n$ values obtained from these standard methods were re- garded as the prototype values for the centrifuge models. A pressure head of up to $-2 \mathrm{~m}$ was applied for the hangingcolumn tests.

Forward simulations were carried out using these values as input parameters. Calculated transient cumulative outflow and pressure profiles were taken as those of the prototype and compared with the centrifuge model results.

\section{Test results and discussion}

\subsection{Measurements from centrifuge models}

Figure 5 shows the cumulative outflow plotted using the scaling relationships with a scale factor $N$. The cumulative outflow is expressed as the outflow volume per unit cross sectional area of the sample. In Fig. 6, the measured pore water pressure profiles are represented at the cumulative outflow volumes in prototype scale at 100 and $400 \mathrm{~mm}^{3} / \mathrm{mm}^{2}$ and at the end of the tests. The test measurement results both in Figs. 5 and 6 are associated with the corresponding prototype profiles calculated from the forward simulations as described in the previous section. In Fig. 5, the differences between the prototype simulations are in the scaled thickness of the screen layer.

As soon as the valve opened, an increase in the cumulative outflow and a decrease in the pore water pressure instantaneously occurred. The increment of the cumulative outflow was initially almost linear and then asymptotically slowed down. Pore water pressure, which was distributed at the initial hydrostatic condition having the atmospheric value found at the soil surface, was shifting toward a new hydrostatic condition with the atmospheric value at the bottom of the soil sample. It was seen from the prototype pressure profiles that the pressure closer to the bottom reached the equilibrium condition sooner than those near the soil surface. At $Q_{N}=400 \mathrm{~mm}^{3} / \mathrm{mm}^{2}$, the pore water distribution at the depth of $1.5 \mathrm{~m}$ or lower had already established a nearly hydrostatic condition while the decrease in the pore water pressure at the upper part was still in progress.

The pore water pressure profiles measured from the tests at $10 \mathrm{~g}$ and $20 \mathrm{~g}$ fell in a narrow range in the vicinity of the corresponding prototype profiles. In contrast, the tests at $40 \mathrm{~g}$ resulted in very poor agreements. The authors consider that 
the slower and lesser pressure changes in the tests at $40 \mathrm{~g}$ might be attributed to cavitation of the ceramic attached on the tensiometers due to rapid pore water pressure drop and the flow impedance of the perforated plate. Entrapped or dissolved air, if existing in the tensiometers, would change its volume in accordance with pore water pressure changes, leading to a delay in the response time, and eventually inducing cavitation. The occurrence of cavitation can be particularly inferred from the inconsistency of measured pressures in the upper part of the soil where the rate of the pressure change is more than in the lower part. Since such a cavitation effect was not seen in the tests at $10 \mathrm{~g}$ and $20 \mathrm{~g}$, in which the tensiometers were prepared in the same manner as the tests at $40 \mathrm{~g}$, it is considered that cavitation occurred at $40 \mathrm{~g}$ due to the more rapid pore water pressure change, especially at the initial stage of the drainage, than in the tests at $10 \mathrm{~g}$ or $20 \mathrm{~g}$. In addition to cavitation, underestimation of flow impedance by the screenn layer in the prototype simulation might be also a part of the discrepancy between the test measurements and the prototype. In this study, the same perforated plate was used for all centrifuge tests, and resulted in the relative thickness of the perforated plate to the soil sample height for the tests at $40 g$ being the largest among the three test conditions. The larger relative thickness of the perforated plate could magnify the disparity between the input hydraulic conductivity value of the perforate plate, which was determined from the constant head permeability tests, and the actual value. The input hydraulic conductivity of the perforated plate was supposed be reasonably accurate since the measured pressure profiles and those of the prototype are in a good agreement in the tests at $10 \mathrm{~g}$ and $20 \mathrm{~g}$, but the accuracy might not be enough to describe the test condition in the tests at $40 \mathrm{~g}$. Based on observations of the pore water pressure measurements, it is matter of course that further improvements to the miniature tensiometers, and the tensiometer saturation procedures are needed for more reliable measurements in centrifuge tests at higher gravity fields (e.g., Take and Bolton, 2002). Additionally, more accurate identification of the hydraulic conductivity of the perforated plate, perhaps for the flow velocity range seen in the targeting centrifuge tests, is also needed.

As for the cumulative outflow, all three prototype curves over time taken in a logarithmic scale fell in a very narrow range as seen in Fig. 5 and all centrifuge tests agreed well with each other until the outflow reached approximately $60 \%$ of the final drainage $\left(Q_{N}=300 \mathrm{~mm}^{3} / \mathrm{mm}^{2}\right)$. The final scaled cumulative outflow was fairly consistent, ranging from $472 \mathrm{~mm}^{3} / \mathrm{mm}^{2}$ to $511 \mathrm{~mm}^{3} / \mathrm{mm}^{2}$. A strong gravity dependency on cumulative outflow was not identified but the results seem to be rather scattered in a narrow range. However, although it is not apparent, the measured cumulative outflows are likely to be more than the prototype values that ended at $490 \mathrm{~mm}^{3} / \mathrm{mm}^{2}$ at $1 \times 10^{5} \mathrm{~min}$.

In addition to the experimental accuracy, the flow rate dependency of the unsaturated flow process and the non-
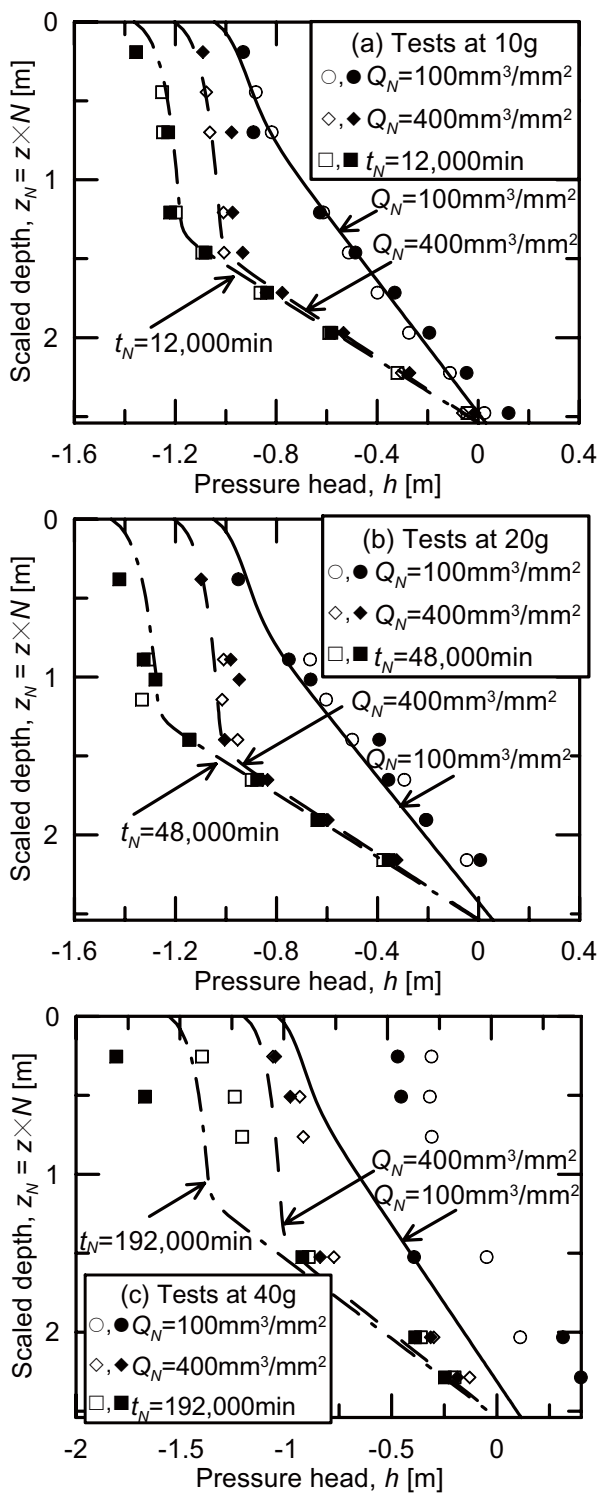

Fig. 6. Pressure responses during drainage; tests at (a) 10g, (b) $20 \mathrm{~g}$, and (c) 40g: the lines are the corresponding prototype profiles calculated by forward simulations with input parameters determined from standard laboratory tests.

scalability of the capillary force in centrifuge models need to be considered for unsaturated flow in centrifuge models. While the unsaturated hydraulic characteristics are often assumed to be identical for steady or transient conditions, a number of researchers have suggested that this assumption is not always justifiable (e.g., Topp et al., 1967; Smiles et al., 1971; Vachaud et al., 1972; Wildenschild et al., 2001; Oung et al., 2005). Wildenschild et al. (2001) conducted one-step and multi-step outflow experiments as well as quasistatic experiments on identical samples of sandy and loamy soils to evaluate the influence of flow rate on the calculated 

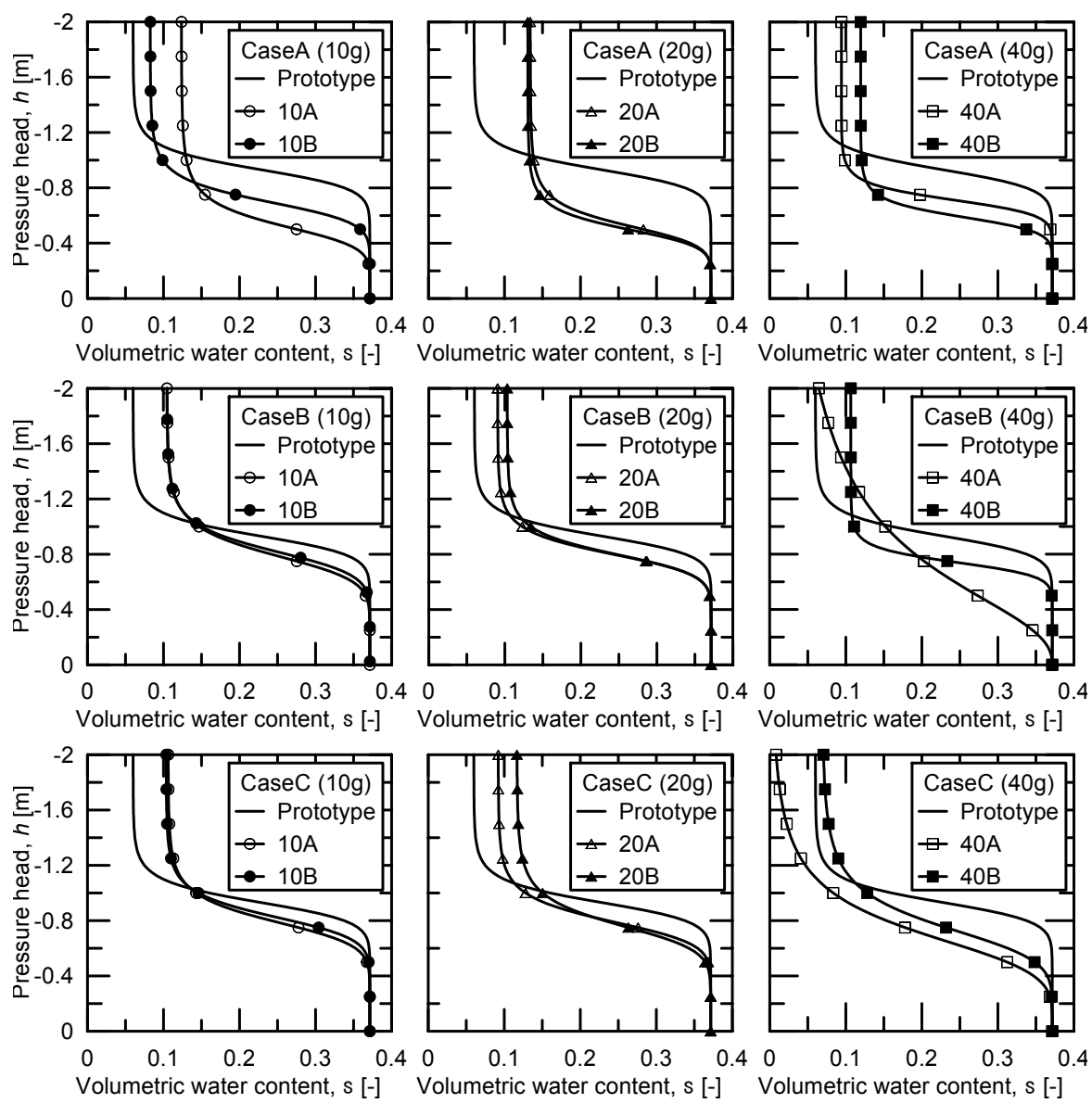

Fig. 7. Predicted retention curves with input data set (a) (first row), (b) (second row), and (c) (third row).

unsaturated hydraulic parameters. The authors found that soil water retention for sandy soil, which had a relatively uniform pore size distribution, increases as the number of pressure steps decreases, with the largest retention and residual water content from the one-step experiment and the lowest retention and the residual water content from the quasistatic syringe pump and low-pressure multi-step outflow experiments. In contrast, no apparent rate dependency was observed from tests with fine textured sandy loam. Among the five factors which Wildenschild et al. (2001) noted affecting flow rate dependency, the entrapment of water could possibly occur in centrifuge tests. Water entrapment is thought to occur through the hydraulic isolation of water-filled pores by draining the surrounding pores. The larger the drainage rate, the less opportunity exists for all pores to drain concurrently leading to an increased water retention value. The flow rate dependency may also be explained by the microscopic capillary number. When the dominant length scale for the drainage is microscopic, violation of the scaling similitude by a large viscous force relative to the capillary force may result in a slower outflow rate in a higher gravity field. The en- trapment of pore water and the violation of the microscopic capillary number are the most likely affect, if they are significant, the outflow at the initial stage rather than the later stage. However, since the measured cumulative outflows were more consistent with each other and almost identical to their prototypes at the initial stage, these two flow rate dependencies were considered to be relatively insignificant.

Conversely, the violation of the microscopic Bond number could act to increase the outflow volume in a centrifuge field. The violation of the similitude between the body and capillary forces ought to lead to more drainage from the upper part of the soil where the microscopic length is more dominant compared to the more saturated lower part, and such excess drainage would likely occur not at an initial stage but when the saturation becomes low enough for pore water to be discontinuous. As a general trend, violation of the microscopic Bond number agrees with a larger cumulative outflow volume at a later stage than in the prototypes. This may be also determined from the slightly more negative pore water pressures seen at the measurement points near the soil surface at the very final measurements (see measurements of $0.2 \mathrm{~m}$ 
deep at $12000 \mathrm{~min}$ in 10B, $0.4 \mathrm{~m}$ deep at $48000 \mathrm{~min}$ in 20B, and $0.25 \mathrm{~m}$ and $0.5 \mathrm{~m}$ deep at $192000 \mathrm{~min}$ in $40 \mathrm{~B}$ ), while it is seen from the tests at $10 \mathrm{~g}$ and $20 \mathrm{~g}$ that the pressure measurements at a depth approximately below $1.5 \mathrm{~m}$ resulted in good agreements with the prototype profiles even at the final stage. However, this inference is not firmly conclusive since an apparent gravity dependence was not observed from the cumulative outflow and pressure measurements in the $40 \mathrm{~g}$ tests seem insufficiently trustworthy.

Nevertheless, the excellent agreements of the pressure profiles between the prototypes and the centrifuge models at $10 \mathrm{~g}$ and $20 \mathrm{~g}$ and the narrow range which the cumulative outflow measurements fell in indicate that the scaling similitude of unsaturated flow was reasonably conserved at least up to $20 \mathrm{~g}$ and highlight the possibility to use the centrifuge modeling technique for one-step parameter estimations.

\subsection{Inverse analysis results}

Inverse analyses were performed to determine the unsaturated hydraulic parameters from the data acquired in the centrifuge tests. Each analysis was implemented for the prototype scale conditions in the same manner as previously described. The saturated hydraulic conductivity of the perforated plate was used in the inverse analyses as a known parameter, and four parameters of the soil sample, $\theta_{r}, \alpha, n$, and $K_{s}$ values, were set as unknowns to be optimized. Three types of data sets were considered; (Case A): cumulative outflows at approximately every $50 \mathrm{~mm}^{3} / \mathrm{mm}^{2}$ increments in the prototype scale, (Case B): cumulative outflow data as in (Case A) and pore water pressure changes measured at a middepth of the soil at times corresponding to the cumulative outflow data set of (Case A), and (Case C): the same data set as (B) plus the final pore water pressure measurements from multiple locations. Inverse analyses using cumulative outflow and pore water pressure head data as functions of time from one-step tests were carried out to optimize $\theta_{r}, \alpha, n$, and $K_{s}$ by Eching and Hopmans (1993). Their results showed improvements with respect to uniqueness and sensitivity by adding the pore water pressure head measurements and good agreements between optimized retention characteristics and those obtained from direct measurements. Therefore, a priori, we assumed that the soil retention characteristics taking the four unknown parameters can be adequately optimized by using these types of measurement data.

Assuming that the measurement errors within each measurement type are independent, uncorrelated, and normally distributed, a weighted least squares problem represents the maximum likelihood estimator. Weighting factor values can be selected to be equal to the reciprocal of standard error of the measurements (Hollenbeck and Jensen, 1998). By assuming actual values of the cumulative outflow or pore water pressure head were within measured values \pm the measurement accuracy with $95 \%$ confidence, the standard error of outflow and pore water pressure measurements were estimated approximately to $\sigma_{Q} \approx 0.05 / 1.96=0.025 \mathrm{~mm}^{3} / \mathrm{mm}^{2}=0.25 \mathrm{~cm}^{3} / \mathrm{cm}^{2}$ and $\sigma_{h} \approx 2 / 1.96=1 \mathrm{~mm}=0.1 \mathrm{~cm}$, respectively. The weighting factors in Eq. (8) were then defined as $w_{i}=1 / 0.25=4$ and $v_{1} v_{2_{k}}=1 / 0.1=10$. It should be noted, however, that the estimated standard error of the pore water pressure head measurements is likely underestimated, especially for the tests at high gravity fields. Because the pressure sensor calibration tests were conducted under pneumatically controlled condition without soil, the accuracy of the pore water pressure head measurements estimated from the calibration tests does not account for the effects of entrapped air or eventual cavitaion of the ceramics.

As the initial estimates, different sets of parameter values randomly chosen within $0 \leq \theta_{r} \leq 0.2,0.1 \leq \alpha[1 / \mathrm{m}] \leq 3$, $2 \leq n \leq 15$, and $3 \times 10^{-6} \leq K_{s}[\mathrm{~m} / \mathrm{s}] \leq 3 \times 10^{-4}$ were used to test uniqueness of an optimized solution. Among the optimized parameter sets excluding unrealistic results, a set with the highest $r^{2}$ for each case was taken as the representative. Table 4 shows the optimization results accompanied by standard error coefficients and the root-mean-square error (RMSE). The RMSE relating to the water retention characteristics is defined as

RMSE $=\left[\frac{1}{D} \sum_{i=1}^{D}\left\{\theta_{\text {proto }}\left(h_{i}\right)-\theta_{\text {opt }}\left(h_{i}\right)\right\}^{2}\right]^{\frac{1}{2}}$

where $D=100$ is the number of data points, $\theta_{\text {proto }}\left(h_{i}\right)$ and $\theta_{\text {opt }}\left(h_{i}\right)$ are water contents calculated with the prototype or the optimized parameter values at pore water pressure head $=h_{i}$, respectively. Figure 7 shows the predicted retention curves.

As expected, the predictions with Case A are mostly much different from the prototype retention curve. $\theta_{r}$ ranges from 0.082 to 0.134 and an air-entry value, which is defined as the pressure head when the pore water can begin to drain from the soil, ranges from approximately $-0.3 \mathrm{~m}$ to $-0.5 \mathrm{~m}$ while the prototype retention curve has the air-entry value of approximately $-0.7 \mathrm{~m}$. The retention curves predicted from 10B, 40A, and 40B are relatively close to the prototype curve but the inconsistency of the predictions seen from the tests at $10 \mathrm{~g}$ and $40 \mathrm{~g}$ indicates that outflow data do not provide sufficient information to uniquely determine the four unknown parameters.

Adding pore water pressure head information to the input data as was done in Cases $\mathrm{B}$ and $\mathrm{C}$ resulted in much better predictions than in Case A for the tests at $10 \mathrm{~g}$ and $20 \mathrm{~g}$. The predicted retention curves from the tests at $10 \mathrm{~g}$ and $20 \mathrm{~g}$ are in a reasonably narrow range, close to the prototype retention curve, especially where the pressure head is from 0 to $-1 \mathrm{~m}$, and are consistent. $\theta_{r}$ resulted around 0.1 from Cases B and $\mathrm{C}$ at $10 \mathrm{~g}$ and $20 \mathrm{~g}$. Better predictions from Cases B and C are also seen from comparison of the RMSE values. Except 40A, the RMSE values of Cases B and C are 40 to $60 \%$ of those of Case A. Comparing the predicted retention curves 
Table 4. Optimized parameters: Values in parenthesis are standard error coefficients of optimized parameter.

\begin{tabular}{|c|c|c|c|c|c|c|}
\hline \multicolumn{2}{|c|}{ Data set } & $\begin{array}{l}\theta_{r} \\
{[-]}\end{array}$ & $\begin{array}{c}\alpha \\
{[1 / \mathrm{m}]}\end{array}$ & $\begin{array}{c}n \\
{[-]}\end{array}$ & $\begin{array}{c}K_{S} \\
{[\mathrm{~m} / \mathrm{s}]}\end{array}$ & $\begin{array}{c}\text { RMSE } \\
{[-]}\end{array}$ \\
\hline \multicolumn{2}{|c|}{ prototype } & 0.060 & 1.07 & 13 & $3.22 \times 10^{-5}$ & \\
\hline \multirow[t]{6}{*}{ A } & $10 \mathrm{~A}$ & $0.123\left(1.56 \times 10^{-2}\right)$ & $1.93\left(4.40 \times 10^{-1}\right)$ & $6.42\left(1.09 \times 10^{0}\right)$ & $2.62 \times 10^{-5}\left(1.85 \times 10^{-6}\right)$ & $9.00 \times 10^{-2}$ \\
\hline & $10 \mathrm{~B}$ & $0.082\left(6.88 \times 10^{-3}\right)$ & $1.43\left(5.61 \times 10^{-2}\right)$ & $8.90\left(1.73 \times 10^{0}\right)$ & $3.40 \times 10^{-5}\left(8.98 \times 10^{-7}\right)$ & $6.27 \times 10^{-2}$ \\
\hline & $20 \mathrm{~A}$ & $0.134\left(7.78 \times 10^{-3}\right)$ & $1.91\left(1.76 \times 10^{-1}\right)$ & $7.03\left(1.57 \times 10^{0}\right)$ & $2.53 \times 10^{-5}\left(1.21 \times 10^{-6}\right)$ & $9.09 \times 10^{-2}$ \\
\hline & $20 \mathrm{~B}$ & $0.131\left(3.62 \times 10^{-3}\right)$ & $2.00\left(7.86 \times 10^{-2}\right)$ & $7.59\left(7.97 \times 10^{-1}\right)$ & $2.33 \times 10^{-5}\left(5.33 \times 10^{-7}\right)$ & $9.61 \times 10^{-2}$ \\
\hline & $40 \mathrm{~A}$ & $0.094\left(1.29 \times 10^{-2}\right)$ & $1.40\left(8.56 \times 10^{-2}\right)$ & $13.1\left(2.63 \times 10^{0}\right)$ & $2.46 \times 10^{-5}\left(1.42 \times 10^{-6}\right)$ & $6.38 \times 10^{-2}$ \\
\hline & $40 \mathrm{~B}$ & $0.119\left(1.20 \times 10^{-2}\right)$ & $1.70\left(1.21 \times 10^{-1}\right)$ & $10.7\left(3.50 \times 10^{0}\right)$ & $1.58 \times 10^{-5}\left(2.11 \times 10^{-6}\right)$ & $8.65 \times 10^{-2}$ \\
\hline \multirow[t]{6}{*}{ B } & $10 \mathrm{~A}$ & $0.104\left(4.54 \times 10^{-2}\right)$ & $1.27\left(3.24 \times 10^{-2}\right)$ & $8.26\left(6.01 \times 10^{-1}\right)$ & $4.57 \times 10^{-5}\left(9.42 \times 10^{-6}\right)$ & $4.30 \times 10^{-2}$ \\
\hline & 10B & $0.105\left(2.61 \times 10^{-2}\right)$ & $1.22\left(1.74 \times 10^{-2}\right)$ & $9.19\left(3.86 \times 10^{-1}\right)$ & $5.07 \times 10^{-5}\left(6.02 \times 10^{-6}\right)$ & $3.83 \times 10^{-2}$ \\
\hline & $20 \mathrm{~A}$ & $0.091\left(3.18 \times 10^{-2}\right)$ & $1.25\left(2.62 \times 10^{-2}\right)$ & $10.4\left(7.65 \times 10^{-1}\right)$ & $3.11 \times 10^{-5}\left(4.36 \times 10^{-6}\right)$ & $3.80 \times 10^{-2}$ \\
\hline & $20 \mathrm{~B}$ & $0.103\left(2.69 \times 10^{-2}\right)$ & $1.25\left(2.70 \times 10^{-2}\right)$ & $10.3\left(4.52 \times 10^{-1}\right)$ & $3.65 \times 10^{-5}\left(5.57 \times 10^{-6}\right)$ & $4.11 \times 10^{-2}$ \\
\hline & $40 \mathrm{~A}$ & $0.000\left(4.16 \times 10^{-2}\right)$ & $1.71\left(4.24 \times 10^{-1}\right)$ & $2.40\left(1.01 \times 10^{0}\right)$ & $2.66 \times 10^{-5}\left(1.94 \times 10^{-5}\right)$ & $6.85 \times 10^{-2}$ \\
\hline & $40 \mathrm{~B}$ & $0.107\left(3.74 \times 10^{-2}\right)$ & $1.35\left(2.22 \times 10^{-2}\right)$ & $14.7\left(4.70 \times 10^{0}\right)$ & $1.80 \times 10^{-5}\left(2.64 \times 10^{-6}\right)$ & $5.84 \times 10^{-2}$ \\
\hline \multirow[t]{6}{*}{$\mathrm{C}$} & $10 \mathrm{~A}$ & $0.106\left(4.71 \times 10^{-2}\right)$ & $1.27\left(3.15 \times 10^{-2}\right)$ & $8.91\left(5.10 \times 10^{-1}\right)$ & $4.60 \times 10^{-5}\left(9.91 \times 10^{-6}\right)$ & $4.34 \times 10^{-2}$ \\
\hline & 10B & $0.104\left(4.57 \times 10^{-2}\right)$ & $1.21\left(2.69 \times 10^{-2}\right)$ & $10.0\left(5.94 \times 10^{-1}\right)$ & $4.99 \times 10^{-5}\left(1.03 \times 10^{-5}\right)$ & $3.66 \times 10^{-2}$ \\
\hline & $20 \mathrm{~A}$ & $0.092\left(7.70 \times 10^{-2}\right)$ & $1.26\left(6.31 \times 10^{-2}\right)$ & $9.40\left(1.27 \times 10^{0}\right)$ & $3.12 \times 10^{-5}\left(1.11 \times 10^{-5}\right)$ & $3.97 \times 10^{-2}$ \\
\hline & $20 \mathrm{~B}$ & $0.117\left(7.14 \times 10^{-2}\right)$ & $1.31\left(7.61 \times 10^{-2}\right)$ & $8.08\left(5.79 \times 10^{-1}\right)$ & $4.19 \times 10^{-5}\left(1.80 \times 10^{-5}\right)$ & $5.09 \times 10^{-2}$ \\
\hline & $40 \mathrm{~A}$ & $0.003\left(2.25 \times 10^{-1}\right)$ & $1.47\left(2.89 \times 10^{-1}\right)$ & $4.54\left(1.28 \times 10^{0}\right)$ & $1.49 \times 10^{-5}\left(1.06 \times 10^{-5}\right)$ & $7.72 \times 10^{-2}$ \\
\hline & $40 \mathrm{~B}$ & $0.068\left(8.90 \times 10^{-2}\right)$ & $1.36\left(1.16 \times 10^{-1}\right)$ & $5.92\left(6.64 \times 10^{-1}\right)$ & $1.79 \times 10^{-5}\left(5.86 \times 10^{-6}\right)$ & $4.79 \times 10^{-2}$ \\
\hline
\end{tabular}

of case C with those of case B for the tests at $10 \mathrm{~g}$ and $20 \mathrm{~g}$, there is no significant improvement. As for the tests at $40 \mathrm{~g}$, the inclusion of pressure measurement data made the predictions more inconsistent than those in Case A and even worse for 40A. As described in the previous section, the pressure measurements for the tests at $40 \mathrm{~g}$ are not considered to be sufficiently accurate, and the worsened predictions in Cases $\mathrm{B}$ and $\mathrm{C}$ show the importance of measurement accuracy for successful parameter optimization (Kool et al., 1985). Standard error coefficients of $\alpha$ and $n$ for cases B and C became smaller than those for Case A but a reverse trend was seen for $\theta_{r}$ and $K_{s}$ for Eching and Hopmans (1993) the prediction accuracy of all four estimated parameters became smaller when both outflow and pressure head data were included. This may be caused by the different measurement conditions such as measurement locations, frequency, and accuracy from this study. It should be emphasized again that more reliable pore water pressure head measurement and knowledge of the accuracy are necessary to fully interpret the optimized parameter uncertainties.

Due to the lack of validation data for the unsaturated hydraulic characteristics, analyses in this study is limited to the retention curves only. The optimized $K_{s}$ values from all of the tests with any type of input data sets fell in the same order of magnitude as the prototype $K_{S}$ values. $K_{S}$ values from Cases B and C at $10 g$ and $20 g$ are almost identical. Since the information added to Case $\mathrm{C}$ is only the pressure measurements at the time when the drainage was almost finished, the contribution by such additional information for $K_{S}$ prediction is likely not very significant. It should be noted that $K_{s}$ value estimated from the inverse analyses can be not enough to get a reliable estimation of the unsaturated hydraulic conductivity function and it should be regarded as a fitting parameter (Romano and Santini, 1999). In addition, soil hydraulic conductivity at complete saturation has been recognized as a poorly informative parameter for predicting the unsaturated soil hydraulic function from knowledge of the soil water retention function (e.g., Schaap and Leij, 2000).

\section{Conclusions}

In this study, centrifuge modeling of one-step tests at multiple gravity levels was performed. The cumulative outflow 
and transient pore water pressure heads at several locations were measured and compared with the prototype data, which were calculated from forward simulations using input parameters determined from standard laboratory tests, based on the centrifuge scaling laws. The measured cumulative outflow and pore water pressure were then used as input data for parameter estimations by the inverse method.

The scaled cumulative outflow curves showed good agreement with the prototype curve until a point when approximately $60 \%$ of the final outflow volume was drained, and then showed a tendency to become slightly larger than the prototype at a later stage of the drainage. It was considered that a violation of the scaling similitude for body force relative to capillary force occurred when and where the governing length scale became microscopic. However, it should be noted that an apparent gravity dependency was not identified and that the overall cumulative outflow curves still fell in a relatively narrow range. Pressure measurements also showed good agreements with the prototype profiles, except for the tests at $40 \mathrm{~g}$. It was considered that cavitation occurred in the tensiometers and resulted in the pressure measurements for the tests at $40 \mathrm{~g}$ being unsuccessful. Nevertheless, the reasonable agreements of cumulative outflow and pressure profiles infer that unsaturated flow during monotonic drainage was reasonably scaled in the centrifuge model, at least up to $20 \mathrm{~g}$.

The estimated unsaturated parameters compared reasonably well with those determined using standard laboratory tests when accurate pore water pressure measurements were included as input data, while the estimations with only cumulative outflow data led to poorer and less consistent results. The addition of pressure measurements, even at a single location, improved accuracy and consistency for retention characteristics. However, unclear quantification of the actual pore water pressure measurement accuracy during the tests precluded full evaluation of the uncertainties and sensivity of the estimated parameters. For success of parameter estimations, the analyses of parameter uncertainty and sensitivity are imperative along with knowing the measurement accuracy as a prerequisite.

Characterizations of unsaturated hydraulic parameters utilizing centrifugal force are often used, but are typically based on an equilibrium condition or a steady state. Coupling the application of a centrifugal force with the inverse method is advantageous in respect to achieving a shorter testing time. Recently Simunek and Nimmo (2005) performed multirotation experiments with a relatively small size centrifuge for parameter estimations using a numerical code that was specially developed to take into account the radial variations of centrifugal gravity. They showed that centrifuge tests not only offer significant time savings but also provide significantly more information for the parameter estimation procedure compared to the usual one-step or multistep outflow experiments. While the methodology by Simunek and Nimmo (2005) is advantageous, particularly with respect to costeffectiveness and the capability to carry to a very high grav- ity field using the small centrifuge apparatus, the application of the centrifuge "modeling" technique with a relatively larger centrifuge apparatus offers different benefits. Large centrifuges can mount a much larger soil sample and thus provide more freedom to implement a variety of instrumentations at multiple locations, controls of initial and boundary conditions are also much easier, and special consideration of the radial variation of centrifugal acceleration is not necessary for the inverse calculation. The test setup developed for this study enabled us to measure both cumulative outflow and transient pressure data that constitute useful information for parameter estimations.

Based on the results in this investigation, the conservation of scaling similitude for unsaturated flow process, which is likely not exactly conserved, was however reasonably assured up to $20 \mathrm{~g}$. This indicates the potential for successful application of the centrifuge modeling technique to other studies such as contaminant transport under unsaturated conditions. To more confidently use the centrifuge modeling technique for unsaturated flow problems, further investigations and improvements in experimental techniques are necessary. In particular, improving the point-wise measurements of rapid and large pore water pressure changes is a critical issue. With more reliable pore water pressure measurements one should be able to gain information on the optimal experimental and measurement design for inverse methods.

Acknowledgements. This work was supported by the BBWI Corporate Funded Research and Development and the DOE Environmental Systems Research and Analysis Programs. The authors are grateful to J. Lord and J. Johnson for technical support. The authors also acknowledge the valuable comments by J. Nimmo of U.S. Geological Survey, and M. Takeda and K. Ito of the National Institute of Advanced Industrial Science and Technology (AIST). The authors also appreciate helpful comments from the Editor N. Romano.

Edited by: N. Romano

\section{References}

Alemi, M. H., Nielsen, D. R., and Biggar, J. W.: Determining the hydraulic conductivity of soil cores by centrifugation, Soil Sci. Soc. Am. J., 40, 212-218, 1976.

Arulanandan, K., Thompson, P. Y., Kutter, B. L., Meegoda, N. J., Muraleetharan, K. K., and Yogachandran, C.: Centrifuge Modeling of Transport Processes for Pollutants in Soils, J. Geotech. Eng.-Ascel, 114(2), 185-205, 1988.

Burkhart, S., Davies, M. C. R., Depountis, N., Harris, C., and Williams, K. P.: scaling laws for infiltration and drainage tests using a geotechnical centrifuge, Proceeding of the International Symposium on Physical Modelling and Testing in Environmental Geotechnics, 191-198, 2000.

Cooke, B.: Determination of soil hydraulic properties, International Conference Centrifuge 94, 411-416, 1994. 
Cooke, A. B. and Mitchell, R. J.: Physical modelling of a dissolved contaminant in an unsaturated sand, Can. Geotech. J., 28, 829833, 1991.

Crançon, C. G., Pili, E., Dutheil, S., and Gaudet, J. P.: Modelling of capillary rise and water retention in centrifuge tests using time domain reflectometry, Proceeding of the International Symposium on Physical Modelling and Testing in Environmental Geotechnics, 199-206, 2000.

Culligan, P. J. and Barry, D. A.: Similitude requirements for modelling NAPL movement with a geotechnical centrifuge, Proceedings of the Institution of Civil Engineers-Geotechnical Engineering, 131(3), 180-186, 1998.

Eching, S. O. and Hopmans, J. W.: Optimization of Hydraulic Functions from Transient Outflow and Soil-Water Pressure Data, Soil Sci. Soc. Am. J., 57(5), 1167-1175, 1993.

Eching, S. O., Hopmans, J. W., and Wendroth, O.: Unsaturated Hydraulic Conductivity from Transient Multistep Outflow and Soil-Water Pressure Data, Soil Sci. Soc. Am. J., 58(3), 687-695, 1994.

Garnier, J.: Physical models in geotechnics: state of the art and recent advances, First Coulomb lecture (Caquot Conference, 3rd October, Paris), 1-51, 2001.

Goforth, G. F., Townsend, F. C., and Bloomquist, D.: Saturated and unsaturated fluid flow in a centrifuge, Centrifuge 91. Proceedings of the International Conference on Centrifuge Modelling, 497$502,1991$.

Hagoort, J.: Oil-Recovery by Gravity Drainage, Soc. Petroleum Eng. J., 20(3), 139-150, 1980.

Hassler, G. L. and Brunner, E.: Measurement of capillary pressures in small core samples, Transactions of the American Institute of Mining and Metallurgical Engineers, 160, 114-123, 1945.

Hensley, P. J. and Schofield, A. N.: Accelerated Physical Modeling of Hazardous-Waste Transport, Geotechnique, 41(3), 447-465, 1991.

Hollenbeck, K. J. and Jensen, K. H.: Maximum-likelihood estimation of unsaturated hydraulic parameters, J. Hydrol., 210, 192205, 1998.

Hopmans, J. W., Vogel, T., and Koblik, P. D.: X-ray tomography of soil water distribution in one-step outflow experiments, Soil Sci. Soc. Am. J., 56, 355-362, 1992.

Hopmans, J. W., Simunek, J., Romano, N., and Durner, W.: Simultaneous determination of water transmission and retention properties. Inverse Methods, in: Methods of Soil Analysis. Part 4. Physical Methods, edited by: Dane, J. H. and Topp, G. C., Soil Sci. Soc. Am., 5, 963-1008, 2002.

Khalifa, A., Garnier, J., Thomas, P., and Rault, G.: scaling laws of water flow in centrifuge models, International Symposium on Physical Modelling and Testing in Environmental Geotechnics, 56, 207-216, 2000.

Khanzode, R. M., Vanapalli, S. K., and Fredlund, D. G.: Measurement of soil-water characteristic curves for fine-grained soils using a small-scale centrifuge, Can. Geotech. J., 39, 1209-1217, 2000.

Knight, M. A., Cooke, A. B., and Mitchell, R. J.: Scaling of the movement and fate of contaminant releases in vadose zone by centrifuge testing, International Symposium on Physical Modelling and Testing in Environmental Geotechnics, 233-242, 2000.
Kool, J. B., Parker, J. C., and van Genuchten, M. T.: Determining Soil Hydraulic-Properties from One-Step Outflow Experiments by Parameter-Estimation .1. Theory and Numerical-Studies Centrifuge tests on moisture and permeability in sand, Soil Sci. Soc. Am. J., 49(6), 1348-1354, 1985.

Mualem, Y.: A new model for predicting the hydraulic conductivity of unsaturated porous media, Water Resour. Res. 12, 513-522, 1976.

Nakajima, H., Hirooka, A., Takemura, J., and Marino, M. A.: Centrifuge modeling of one-dimensional subsurface contamination, J. Am. Water Resour. Assoc., 34(6) 1415-1425, 1998.

Nakajima, H., Kutter, B. L., Ginn, T. R., Chang, D. P., and Marino, M. A.: An experimental study of LNAPL lens formation using a centrifuge, Proceedings of the 16th International Conference on Soil Mechanics and Geotechnical Engineering, 4, 2425-2428, 2005.

Nimmo, J. R., Rubin, J., and Hammermeister, D. P.: Unsaturated Flow in a Centrifugal Field - Measurement of Hydraulic Conductivity and Testing of Darcy Law, Water Resour. Res., 23(1), 124-134, 1987.

Oung, O., Hassanizadeh, S. M., and Bezuijen, A.: Two-phase flow experiments in a geocentrifuge and the significance of dynamic capillary pressure effect, J. Porous Media, 8(3), 247-257, 2005.

Parker, J. C., Kool, J. B., and van Genuchten, M. T.: Determining Soil Hydraulic-Properties from One-Step Outflow Experiments by Parameter-Estimation .2. Experimental Studies, Soil Sci. Soc. Am. J., 49(6), 1354-1359, 1985.

Rezzoug, A., König, D., and Triantafyllidis, T.: scaling laws for centrifuge modeling of capillary rise in sandy soils, J. Geotech. Geoenviron. Eng., 130(6), 615-620, 2004.

Romano, N. and Santini, A.: Determining soil hydraulic functions from evaporation experiments by a parameter estimation approach: Experimental verifications and numerical studies, Water Resour. Res., 35(11), 3343-3359, 1999.

Russell, M. B. and Richards, L. A.: The determination of soil moisture energy relations by centrifugation, Soil Sci. Soc. Am. Proceedings, 3, 65-69, 1938.

Schaap, M. G. and Leij, F. J.: Improved prediction of unsaturated hydraulic conductivity with the Mualem-van Genuchten model, Soil Sci. Soc. Am. J., 64, 843-851, 2000.

Simunek, J., Sejna, M., and van Genuchten, M. T.: The HYDRUS1D software package for simulation of the one-dimensional movement of water, heat and multiple solutes in variably saturated media, Version 2.0, International Ground Water Modelling Center, IGWMC-TPS-70, 1998.

Simunek, J. and Nimmo, J. R.: Estimating soil hydraulic parameters from transient flow experiments in a centrifuge using parameter optimization technique, Water Resour. Res., 41(4), W04015, doi:10.1029/2004WR003379, 2005.

Smiles, D., Vachaud, G., and Vauclin, M.: A test of the uniqueness of the soil moisture characteristic during transient nonhysteretic flow of water in a rigid soil, Soil Sci. Soc. Am. Proceedings, 35, 534-539, 1971.

Smith, R. W., Payne, S. M., and Miller, D. L.: INEEL environmental geocentrifuge facility developments International Conference on Physical Modelling in Geotechnics - ICPMG 02, 55-58, 2002.

Take, W. A. and Bolton, M. D.: A new device for the measurement of negative pore water pressures in centrifuge models, In- 
ternational Conference on Physical Modelling in Geotechnics ICPMG 02, 89-94, 2002.

Taylor, R. N.: Geotechnical Centrifuge Technology, Blackie Academic and Professional, 1995.

Thorel, L., Noblet, S., Garnier, J., and Bisson, A.: Capillary rise and drainage flow through a centrifuged porous medium, Proceeding of the International Symposium on Physical Modelling and Testing in Environmental Geotechnics, 251-258, 2000.

Toorman, A. F., Wierenga, P. J., and Hills, R. G.: Parameter estimation of hydraulic properties from one-step outflow data, Water Resour. Res., 28(11), 3021-3028, 1992.

Topp, G. C., Klute, A., and Peters, D. B.: Comparison of water content-pressure head data obtained by equilibrium, steady-state and unsteady state methods, Soil Sci. Soc. Am. Proceedings, 31, 312-314, 1967.
Vachaud, G., Vauclin, M., and Wakil, M.: A study of the uniqueness of the soil moisture characteristic during desorption by vertical drainage, Soil Sci. Soc. Am. Proceedings, 36, 531-532, 1972.

van Dam, J. C., Stricker, J. N. M., and Droogers, P.: Inverse Method for determining soil hydraulic functions from one-step outflow experiments, Soil Sci. Soc. Am. J., 56, 1042-1050, 1992.

van Dam, J. C., Stricker, J. N. M., and Droogers, P.: Inverse method to determine soil hydraulic functions from multistep outflow experiments, Soil Sci. Soc. Am. J., 58(3), 647-652, 1994.

van Genuchten, M. T.: A closed-form equation for predicting the hydraulic conductivity of unsaturated soils, Soil Sci. Soc. Am. J., 44, 892-898, 1980.

Wildenschild, D., Hopmans, J. W., and Simunek, J.: Flow rate dependence of soil hydraulic characteristics, Soil Sci. Soc. Am. J., 65(1), 35-48, 2001. 